Belichenko A.S., ORCID 0000-0001-5938-1555, post-graduate student, Saint Petersburg State University, Saint Petersburg, Russian, belichenko_spgu@list.ru

\title{
Features of functioning of the Internet economy and digital agencies in the Russian Federation
}

This article discusses the features of the functioning of digital agencies in the Internet economy of the Russian Federation. The author of scientific work presented market analysis customized web development and marketing, including the basic parameters of the market, property supply and demand, consumption structure of services, the industry's contribution to the Internet economy, the issues of digitalization, the role of the Russian outsourcing IT-companies in the international arena. The main problems facing the Internet economy market are analyzed and methods of their solution are proposed. Based on the study of the conceptual framework of the topic of scientific work, as well as based on the works of economists, leading programmers and consulting companies, the author examines the economic nature of the functioning of full-service agencies, in particular their Russian specifics. The analysis of programs and reforms that regulate the new rules for the use of digital technologies in the legislation of the Russian Federation, and their impact on improving the efficiency of technological entrepreneurship, was also carried out.

Keywords: IT, digital, marketing, web, promotion, production, design, infrastructure, internet economy

\section{Introduction}


igitalization covers a wide range of new ways to use information technologies and mass communications in products, as well as business models that transform the economy and society. The Internet economy creates new business sectors and destroys old ones. However, the lack of consensus on what the "digital economy", "digital business" and "Internet economy" are is a barrier to its correct measurement.

Digitalization is spreading to an increasing number of industries and segments, from agriculture to construction. But if you define the digital economy based on the use of technology by companies, it will cover most of the state's economy. This definition may be correct, but it is not of great interest to economic researchers: it is equivalent to calling the economy "electric".

If you look at the Western countries In Europe, the share of the digital economy in the broad sense of this term will reach 80
$90 \%$, while the share of the ICT sector itself will not exceed $10 \%$. The direct contribution of ICT to the entire EU economy in 2012 was measured as $1.7 \%$ of GDP, while the indirect contribution, through productivity improvements, digital B2B Commerce and advertising platforms, and free services (all that GDP does not reflect) was $6.7 \%$ of GDP. At the same time, researchers from Copenhagen Economics [1], noted that this is a conservative estimate that does not take into account, for example, the value and utility created by social networks.

There is also no generally accepted definition of the digital economy in international documents. The UN classifiers contain concepts such as the ICT sector and the content and media sector, but ICT products are in turn combined with media and content for statistical purposes. At the same time, the activities of platforms from Alibaba to Airbnb are generally difficult to classify, especially when calculating cross - border operations. Data is not classified in any way - it is not 